\title{
Level of physical activity and quality of life: a comparative study among the elderly of rural and urban areas
}

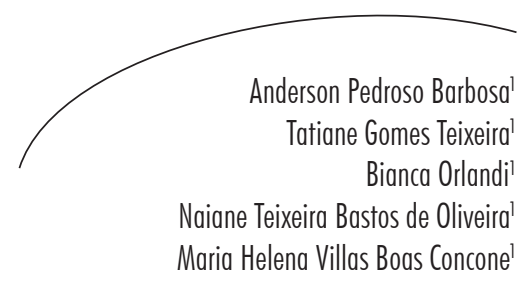

Abstract

Objective: To investigate if the relationship between physical activity level (PAL) and quality of life (QOL) is affected by living environment (rural or urban). Method: A quantitative, observational and cross-sectional study was performed. Of the 40 participants of both genders, 20 were residents of urban areas and 20 were residents of rural areas in the town of Pimenta Bueno (RO), Brazil. The WHOQOL BREF and IPAQ Long Version questionnaires were used to assess QOL and PAL, respectively. Mann Whitney and Fisher's Exact were used to statistically compare groups for QOL and PAL scores. The correlation between the two was tested by the Spearman test. A significance level of $p<0.05$ was used. Results: No differences between the rural and urban areas for QOL or PAL were found. In the rural group a positive and significant correlation was found between PAL and the physical, psychological and complete QOL domains. In terms of PAL, elderly persons from the rural area who were regularly active had higher total QOL and physical domain scores than insufficiently active elderly individuals from the rural area. When place of residence was compared, insufficiently active elderly in the urban area had higher scores on the social component of QOL than insufficiently active elderly from the rural group. Among regularly active seniors, those living in the rural area had higher physical QOL scores. Conclusion: According to the results, level of physical activity exerts a differential influence on the QOL of elderly people from rural and urban areas.

Key words: Quality of Life; Physical Activity; Elderly; Aging.

Pontifícia Universidade Católica de São Paulo, Faculdade de Ciências Humanas e da Saúde, Programa de Pós-graduação em Gerontologia. São Paulo, SP, Brasil. 


\section{INTRODUCTION}

Brazil has more than 190 million inhabitants, of which $15.6 \%$ (29 million) live in rural areas. ${ }^{1}$ Urban areas have been defined as those that lie within the urban perimeters of a city or town, as defined by municipal law. The areas that lie outside these urban perimeters are considered rural and are usually used for crops, animal breeding and ecological tourism and other activities. ${ }^{1}$ When compared with urban dwellers, those who live in rural areas are generally less wealthy, with worse living and sanitation conditions, less access to medical services, lower levels of education, an increased risk of injuries linked to the environment or their socioeconomic conditions, and less access to the media. ${ }^{2-5}$ Urban dwellers are largely seen as more technically developed than rural dwellers. In order for the population as a whole to improve, development must occur in both rural and urban areas. ${ }^{6}$ Elderly individuals living in rural areas require special attention, given the fact that biological alterations associated with the aging process, together with the abovementioned characteristics of rural environments, may represent significant vulnerability factors for this section of the population. ${ }^{?}$

Studies ${ }^{5,8,9}$ have shown that elderly individuals living in rural areas have a lower life expectancy and exhibit worse health conditions than elderly individuals living in urban areas. As well as a shorter life span, several studies have indicated that rural dwellers exhibit a lower quality of life (QOL) and perception of wellbeing, whether in general or in specific domains. ${ }^{10-15}$ Although the lower QOL of elderly rural dwellers, when compared with urban dwellers, is not unanimous (previous Brazilian studies ${ }^{16}$ have reported similar and occasionally higher values in a number of QOL domains for elderly rural dwellers), an investigation into the impact of the rural environment on QOL is relevant, given that this measurement has been correlated with the risk of disability and early death. ${ }^{17}$

As well as the peculiarities of rural living, the lower QOL of elderly rural dwellers, as cited in several studies, ${ }^{2,4}$ may be affected by health-related behavior. Studies suggest that a large section of the rural population suffer from energy deficits, ${ }^{18,19}$ eat unhealthy food on a daily basis, including products that are rich in saturated fats and sugars, ${ }^{20}$ and do not engage in physical activity for leisure, although they do exercise on a daily basis as they work/ get around..$^{21}$ Therefore, health-related behavior, together with the peculiarities of rural life, could play a significant role in the QOL of elderly individuals living in rural areas.

Concerning the practicing of physical activities, previous studies have shown that elderly individuals living in rural areas are generally more active than those living in cities, ${ }^{22,23}$ which is mainly due to activities related to their work or the distances covered while getting around. Very few elderly individuals who live in rural areas engage in physical activity for leisure. ${ }^{21}$ Since the correlation between the physical activity level (PAL) and QOL has been previously established in literature, ${ }^{24}$ this absence of a sedentary lifestyle among elderly rural dwellers, when compared with urban dwellers, led to the following contradiction in the present study: although they engage in more physical activity, elderly individuals living in rural areas recorded lower QOL scores.

Is the correlation between QOL and the PAL affected by the location where the elderly individuals live? Or do physical activities practiced while working and getting around have less of an effect on QOL? The initial hypothesis was that rural dwellers are more active than urban dwellers, and that there is a positive correlation between the PAL and QOL in both rural and urban areas.

Therefore, the aim of the present study was to investigate the existence of differences in the quality of life and physical activity levels of elderly individuals living in urban and rural areas.

\section{METHODS}

The design of the present study was crosssectional, quantitative and observational. Data was collected in June, July and August of 2012. Twenty elderly individuals from a rural area and twenty 
elderly individuals from an urban area took part in the present study. These 40 individuals were selected at random, based on a convenience sample. They all fulfilled the following inclusion criteria: (1) they lived in the municipality of Pimenta Bueno, Rondônia; (2) they were aged 60 years or more; and (3) they were able to complete the questionnaires.

In order to assess QOL, the abbreviated version of the WHOQOL (WHOQOL BREF) was used. This questionnaire was created by the World Health Organization (WHO) and translated and validated for use in Brazil by Fleck et al. ${ }^{25}$ The instrument contains 26 items, with two general questions about QOL. The remaining 24 questions are divided into four domains: (a) physical; (b) psychological; (c) social relationships and (d) environment. The responses to the questions range from 1 to 5 , with the worst conditions classified as 1 and the best conditions classified as 5. The WHOQOL BREF contains standardized calculations that rank values between 0 and 100, with the worst results closest to 0 . The psychometric characteristics of the WHOQOL BREF fulfill the criteria of internal consistency, discriminant validity, concurrent validity, content validity and reliability. ${ }^{25}$

The long version of the IPAQ questionnaire was used to assess the PAL. This instrument enabled the weekly time spent performing physical activities in different situations (work, domestic tasks, transport and leisure) to be estimated, as well as the time spent in passive activities (performed while seated). Based on the responses obtained, the individual was classified in terms of physical activity levels using the following categories: sedentary; irregularly active; active; very active.

These categories were defined as follows: 1) Sedentary: individuals who never perform 10 minutes of continuous physical activity in a week; 2) Irregularly active: individuals that perform physical activity, although not enough to be classified as active according to the recommendations for frequency or duration; 3) Active: individuals that perform: a) vigorous physical activity $\geq 3$ days/ week and $\geq 20$ minutes per session; or b) moderate physical activity or walking $\geq 5$ days/week and $\geq 30$ minutes per session; or c) any physical activity $\geq 5$ days/week and $\geq 150$ minutes/week; 4) Very active: individuals that perform: a) vigorous physical activity $\geq 5$ days/week and $\geq 30$ minutes per session or; b) vigorous physical activity $\geq 3$ days/week and $\geq 20$ minutes per session + moderate physical activity or walking $\geq 5$ days/week and $\geq 30$ minutes per session.

Statistical analysis was performed using Stata software (version 12.1). The data was displayed using descriptive statistics (mean and standard deviation), as well as absolute and relative frequency values for the binary and ordinary variables. The internal validity of the questionnaires was assessed using the Cronbach alpha coefficient, the results of which indicated satisfactory indices: $\alpha>0.80$ (WHOQOL BREF) and $\alpha=0.78$ (IPAQ).

The Mann Whitney test was used to determine differences between the QOL (WHOQOL BREF) of the urban and rural groups. Fisher's exact test was used to analyze differences in the PAL between the two groups. Correlations between the PAL and QOL scores were determined using Spearman's correlation test, due to the non-parametric distribution of the variables.

The present study was approved by the Research Ethics Committee of the Pontificia Universidade Católica de São Paulo (PUC-SP) under protocol number CAAE 08558512.5.50000.5482/2012. All of the participants signed a free and informed consent form, as per Resolution 196/96 of the National Health Council/Ministry of Health.

\section{RESULTS}

No differences related to age $(p=0,607)$ or sociodemographic factors were found between the elderly individuals living in rural and urban areas (Table 1). However, for the variable marital status, the p-values for married and non-married (separated or widowed) individuals exhibited a marginal significance. Of the 40 elderly individuals assessed, $72.5 \%$ claimed to suffer from a disease (such as hypertension and diabetes), although there was no significant difference between rural (75\%) and urban $(70 \%)$ dwellers. 
Table 1. Sociodemographic characteristics of elderly individuals living in rural and urban areas. Pimenta Bueno, RO, 2012.

\begin{tabular}{lccc}
\hline & Rural Area & Urban Area & p-value\# \\
\cline { 2 - 3 } & $\mathrm{n}(\%)$ & $\mathrm{n}(\%)$ & 0.73 \\
\hline Gender & $7(35)$ & $5(25)$ & \\
Male & $13(65)$ & $15(75)$ & $\mathbf{0 . 0 6 +}$ \\
Female & & & \\
Marital status & $18(90)$ & $12(60)$ & \\
Married & $2(10)$ & $2(10)$ & $0.15^{*}$ \\
Separated & 0 & $6(30)$ & \\
Widowed & & $3(15)$ & \\
Education & $8(40)$ & $12(60)$ & \\
Illiterate & $10(50)$ & $5(25)$ & \\
Primary School & $2(10)$ & $14(70)$ & \\
High school & & $6(30)$ & \\
Have a disease? & $15(75)$ & & \\
Yes & $5(25)$ & & \\
No & &
\end{tabular}

$\mathrm{n}=$ total number; $\%=$ percentage of the sample by living area; \#Fisher's exact test; +comparison between married and unmarried individuals; *comparison between illiterate and educated individuals. The significance value was set at $p<0.05$.

When comparing the urban and rural groups, no significant differences were found for the variable QOL (Table 2), either in terms of the total score and the individual domains (physical, psychological, social relationships and environment). However, for the domain social relationships, the p-value (0.078) indicated a marginally significant difference, with a higher mean for the urban group $(73.3 \pm 13.4$ versus $62.9 \pm 13.9)$ and similar standard deviation values. These results confirmed that elderly individuals living in rural and urban areas had a similar QOL. 
Table 2. Assessment of quality of life based on the domains of the WHOQOL BREF (scale from 0 to 100) for elderly individuals living in rural and urban areas. Pimenta Bueno, RO, 2012.

\begin{tabular}{lccccc}
\hline \multirow{2}{*}{$\begin{array}{c}\text { WHOQOL BREF } \\
\text { domains }\end{array}$} & \multicolumn{2}{c}{$\begin{array}{c}\text { Rural Area } \\
(\mathrm{n}=20)\end{array}$} & \multicolumn{2}{c}{$\begin{array}{c}\text { Urban Area } \\
(\mathrm{n}=20)\end{array}$} & \\
\cline { 2 - 5 } & Mean $(\mathrm{sd})$ & Range & Mean $(\mathrm{sd})$ & Range & \multirow{2}{*}{$p^{*}$} \\
\hline Physical & $63.7( \pm 17.5)$ & $(17.9-92.9)$ & $60.7 \pm 15.6)$ & $(28.6-89.3)$ & 0.3779 \\
Psychological & $76.3( \pm 8.5)$ & $(50-87.5)$ & $74.2( \pm 12.4)$ & $(50-95.8)$ & 0.7116 \\
Social relationships & $62.9( \pm 13.9)$ & $(25-75)$ & $73.3( \pm 13.4)$ & $(58.3-100)$ & 0.0783 \\
Environment & $61.4( \pm 10.3)$ & $(37.5-75)$ & $60.6( \pm 16.2)$ & $(21.9-87.5)$ & 0.9566 \\
Total & $66.0( \pm 10.0)$ & $(34.6-76.9)$ & $65.5( \pm 12.9)$ & $(39.4-84.6)$ & 0.9137 \\
\hline
\end{tabular}

*Mann Whitney test; sd= standard deviation. The level of significance was set at $p<0.05$.

For the analysis of PAL, elderly individuals who were classified as sedentary or irregularly active in the IPAQ were grouped together, forming the sub-group "insufficiently active" (urban areas, $\mathrm{n}=8$; rural areas, $n=9)$. Participants classified as active or very active were grouped together in the sub-group "regularly active" (urban areas, $\mathrm{n}=12$; rural areas, $n=11)$. The results of the IPAQ indicated that the rural and urban groups were very similar $(p=0.945)$ in terms of PAL (Table 3). When the analysis was stratified by the type of physical activity (work environment, domestic environment, means of transport and leisure time), there were also no statistically significant differences between the two groups of elderly individuals (Table 3).
For PAL classification in the domain related to work, individuals who did not work (rural, $n=16$; urban, $n=15$ ) were considered sedentary, whereas those who worked (rural, $n=4$; urban $n=5$ ), were considered active. The main work activities of rural dwellers involved planting and harvesting crops, as well as taking care of animals. The work conducted by those living in urban areas involved domestic tasks in other residences or public employee work. No differences were recorded for gender in rural or urban areas (Table 3). Concerning the time spent sitting, the mean value was $320 \pm 161.8 \mathrm{MET} /$ day for rural dwellers and 332 $\pm 166.9 \mathrm{MET} /$ day for urban dwellers, with no significant difference between the groups $(p=0.839)$. 
Table 3. Classification of the level of physical activity using the domains of the long version of the IPAQ. Pimenta Bueno, RO, 2012.

\begin{tabular}{|c|c|c|c|c|c|}
\hline & \multicolumn{2}{|c|}{ Rural Area } & \multicolumn{2}{|c|}{ Urban Area } & \multirow[b]{2}{*}{$p^{*}$} \\
\hline & $\mathrm{n}$ & $\%$ & $\mathrm{n}$ & $\%$ & \\
\hline Total & & & & & 0.945 \\
\hline Insufficiently active & 9 & 45 & 8 & 40 & \\
\hline Regularly active & 11 & 55 & 12 & 60 & \\
\hline Work & & & & & 0.331 \\
\hline Insufficiently active\# & 18 & 90 & 16 & 80 & \\
\hline Regularly active & 2 & 10 & 4 & 20 & \\
\hline Transport & & & & & 0.500 \\
\hline Insufficiently active & 15 & 75 & 16 & 80 & \\
\hline Regularly active & 5 & 25 & 4 & 20 & \\
\hline Domestic & & & & & 0.751 \\
\hline Insufficiently active & 10 & 50 & 12 & 60 & \\
\hline Regularly active & 10 & 50 & 8 & 40 & \\
\hline Leisure & & & & & - \\
\hline Insufficiently active & 20 & 100 & 20 & 100 & \\
\hline Regularly active & 0 & 0 & 0 & 0 & \\
\hline
\end{tabular}

'\# All of the individuals that did not work were placed in the sedentary category; *Fisher's exact test. Insufficiently active comprises sedentary and irregularly active individuals. Regularly active comprises those classified as active or very active. The level of significance was set at $p<0.05$.

In order to investigate differences in QOL caused by PAL, the two sub-groups were maintained, in accordance with the total score of the IPAQ. Sedentary and irregularly active individuals composed the sub-group insufficiently active (urban, $n=8$; rural, $n=9$ ). Active and very active individuals composed the regularly active group (urban, $n=12$; rural, $n=11$ ). The four groups were compared in terms of QOL (total score, physical domain, psychological domain, social relationships domain and environment domain).

The results of the Mann Whitney test showed that, among elderly rural dwellers, PAL has a significant effect on QOL, particularly in the physical domain. This was not observed among the elderly individuals who lived in urban areas. Regularly active elderly rural dwellers exhibited a higher QOL score than insufficiently active elderly individuals living in the same (rural) areas (71 \pm 5.7

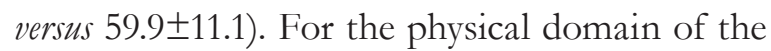
QOL, the same result was found among regularly active elderly individuals, who exhibited a higher score ( $73.7 \pm 9.1$ versus $51.6 \pm 17.9)$ than insufficiently active elderly individuals (Table 4).

The place of residence (rural or urban area) also influenced the social relationships domain of the QOL of the elderly participants. Among those classified as insufficiently active, urban dwellers exhibited a higher QL score for the social relationships domain than rural dwellers $(77.1 \pm 14.6$ versus 57.4 \pm 17.9$)$. For the physical domain of the QL, rural dwellers scored better than urban dwellers, with the same PAL (regularly active) (73.7 \pm 9.1 versus $60.1 \pm 14.4$ ). 
These results demonstrated that, although the QOL and PAL scores in the rural and urban groups were similar, the correlation between the PAL and QOL was effected by the location of the residence (urban and rural). These results were corroborated by those found in the correlation analysis (described below).

Table 4. Quality of life scores (WHOQOL BREF) according to the level of physical activity (IPAQ) of elderly individuals living in rural and urban areas. Pimenta Bueno, RO, 2012.

\begin{tabular}{lcccccccc}
\hline & \multicolumn{2}{c}{ Insufficiently active } & \multicolumn{2}{c}{ Regularly active } & \multicolumn{3}{c}{$p$-value in the Mann Whitney test } \\
$\begin{array}{l}\text { Quality of life } \\
\text { domains }\end{array}$ & $\begin{array}{c}\text { Rural } \\
(\mathrm{n}=9)\end{array}$ & $\begin{array}{c}\text { Urban } \\
(\mathrm{n}=8)\end{array}$ & $\begin{array}{c}\text { Rural } \\
(\mathrm{n}=11)\end{array}$ & $\begin{array}{c}\text { Urban } \\
(\mathrm{n}=12)\end{array}$ & $p \#$ & $p \# \#$ & $p^{*}$ & $p^{* *}$ \\
\hline Total & $59.9( \pm 11.1)$ & $68.6( \pm 12.9)$ & $71( \pm 5.7)$ & $63.5( \pm 13.1)$ & $\mathbf{0 . 0 0 6}$ & 0.177 & 0.374 & 0.165 \\
Physical & $51.6( \pm 17.9)$ & $61.6( \pm 18.2)$ & $73.7 \pm \pm 9.1)$ & $60.1( \pm 14.4)$ & $\mathbf{0 . 0 0 3}$ & 0.334 & 0.757 & $\mathbf{0 . 0 2 8}$ \\
Psychological & $73.1( \pm 10.2)$ & $78.1( \pm 13.1)$ & $78.8( \pm 6.3)$ & $71.5( \pm 11.8)$ & 0.151 & 0.327 & 0.275 & 0.150 \\
Social & $57.4( \pm 17.9)$ & $77.1( \pm 14.6)$ & $67.4( \pm 7.9)$ & $70.8( \pm 12.6)$ & 0.193 & $\mathbf{0 . 0 3 1}$ & 0.323 & 0.774 \\
relationships & & & & & & & & \\
Environment & $58.7( \pm 8.7)$ & $64.8( \pm 14.1)$ & $63,6( \pm 11,4)$ & $57,8( \pm 17,5)$ & 0.155 & 0.308 & 0.535 & 0.370 \\
\hline
\end{tabular}

\# Insufficiently active rural versus regularly active rural; \#\#insufficiently active rural versus insufficiently active urban; *insufficiently active urban versus regularly active urban; ${ }^{* *}$ regularly active rural versus regularly active urban.

The level of significance was set at $p<0.05$.

The final stage of the analysis consisted of an investigation of the correlation between QOL and PAL. The correlation analyses were always conducted between the urban and rural groups. Concerning the total QOL score, a moderately significant correlation was found with PAL for the rural group (Spearman rho $=0.60, p=0.005$ ) (Table 5). This result suggests that in the rural group, an increase in the PAL would lead to an increase in QOL. Figure 1 was designed to better illustrate the correlation between the total QOL and the PAL in the rural and urban groups. As well as the total QOL score, the physical (Spearman rho $=0.69$; $p=0.005)$ and psychological (Spearman rho $=0.46$; $p=0.039)$ domains also demonstrated a correlation with the PAL among elderly rural dwellers.

Table 5. Correlation (Spearman) between the level of physical activity (IPAQ) and the quality of life domains (WHOQOL BREF) of elderly individuals living in rural and urban areas. Pimenta Bueno, RO, 2012.

\begin{tabular}{lcccc}
\hline \multirow{2}{*}{$\begin{array}{c}\text { Level of physical activity versus } \\
\text { quality of life scores }\end{array}$} & \multicolumn{2}{c}{ Rural Area } & \multicolumn{2}{c}{ Urban Area } \\
\cline { 2 - 5 } & rho & $p$ & rho & $p$ \\
\hline Total & 0.60 & $\mathbf{0 . 0 0 5}$ & 0.14 & 0.562 \\
Physical domain & 0.69 & $\mathbf{0 . 0 0 8}$ & 0.35 & 0.127 \\
Psychological domain & 0.46 & $\mathbf{0 . 0 3 9}$ & -0.09 & 0.721 \\
Social relationships domain & 0.34 & 0.142 & 0.13 & 0.597 \\
Environment domain & 0.27 & 0.246 & 0.07 & 0.763 \\
\hline
\end{tabular}

rho $=$ Spearman; $p=$ correlation between activity (insufficiently active and regularly active) and the quality of life domains. The level of significance was set at $p<0.05$. 


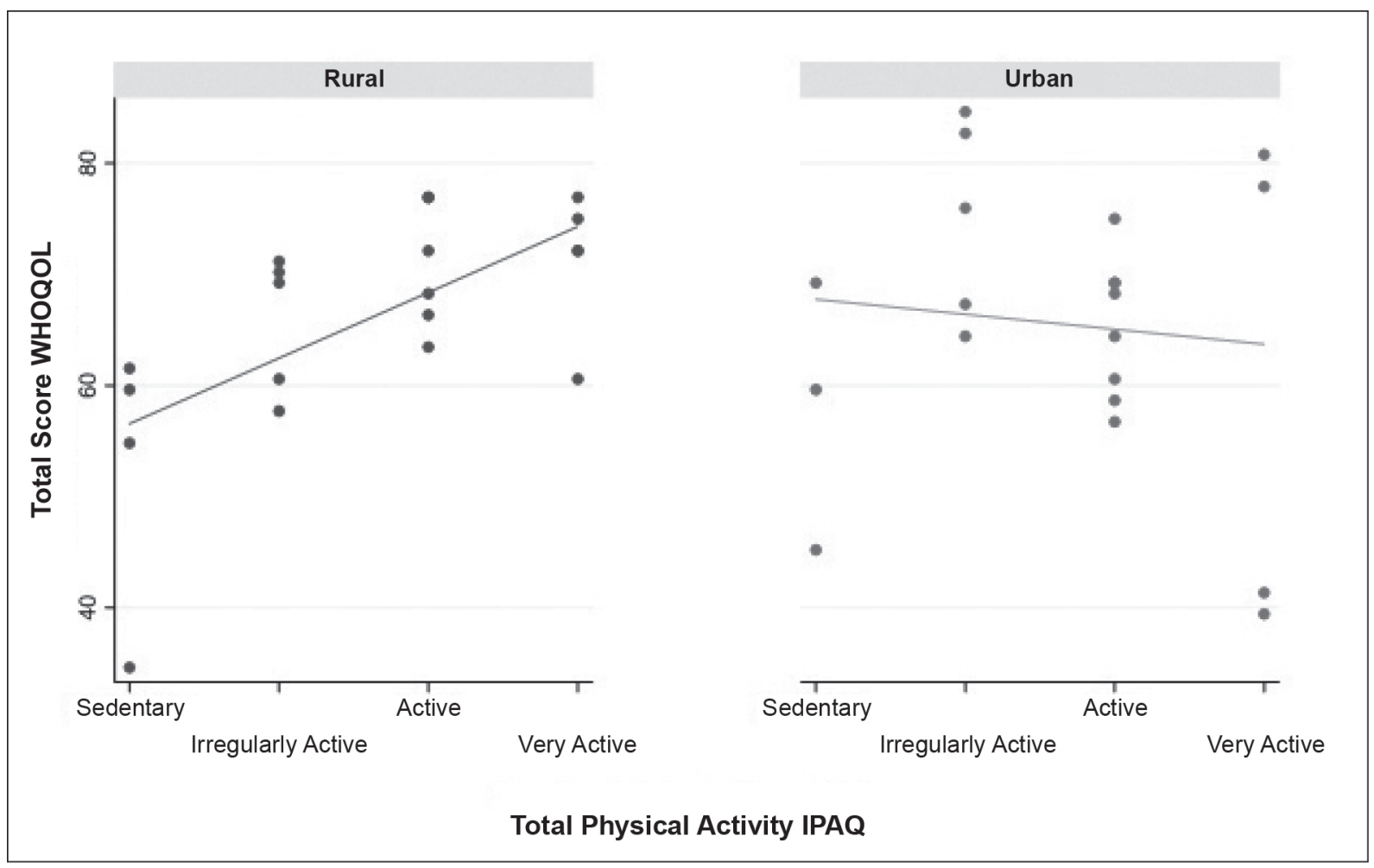

Figure 1. Correlation between the level of physical activity (IPAQ) and the score for total quality of life (WHOQOL BREF) of elderly individuals living in rural and urban areas. Pimenta Bueno, RO, 2012.

\section{DISCUSSION}

The results of the present study indicate that the location of an individual's residence affects the correlation between the PAL and QOL of the elderly individual in question. When compared using only the location of residence, elderly individuals from rural and urban areas exhibited similar values, with no statistical differences for QOL and PAL (Table 3). However, when the groups were organized according to location of residence and PAL, significant results were found. Among insufficiently active individuals, the social component of QOL was higher for urban dwellers, whereas among the regularly active, the physical and total domains of the QOL were higher among rural dwellers (Table 4).

Although the present study is relevant in terms of comparing elderly individuals living in different areas (rural and urban) and different PALs (insufficiently active versus regularly active) in relation to total QOL and its domains (physical, psychological, social relationships, environment), it is important to note that the cross-sectional design prevented the establishment of specific causes for the results obtained. In addition, the scarcity of previous studies containing similar data analysis (the correlation between QOL, PAL and the location of the residence) prevented a definition of the explanations for the results. Therefore, this discussion section presents hypotheses for the possible causes of the results described. The nature of the daily activities performed and the large distances covered in rural areas are significant factors when seeking an understanding of these results.

Considering that insufficiently active elderly individuals generally exhibit less functional capacity and mobility, ${ }^{26}$ it is possible that the lower score in the social domain of the QOL recorded by insufficiently active elderly rural dwellers (when compared with insufficiently 
active elderly urban dwellers) was affected by the characteristics of the different living environments. The urban environment probably favored frequent social contact (when compared with the rural environment) for people with less mobility, due to the smaller distances and greater transport options available. ${ }^{27}$ This explains why the social QOL was only affected by the location of the residence among insufficiently active elderly individuals. Regularly active elderly individuals probably exhibited less mobility impairments and could visit friends and family members more often, thereby contributing to their satisfactory social life. This hypothesis requires further investigation before it can be substantiated.

In contrast to the literature, these results suggest that the social QOL of elderly individuals who live in small towns could be better than that of those who live in large urban centers. In a study by Beltrame et al., ${ }^{17}$ conducted in the city of Concórdia-SC (population 71,000), ${ }^{1}$ which is more than double the size of the town used in the present study (Pimenta Bueno-RO), it was reported that the social QOL of elderly individuals living in large cities is worse than the social QOL of those who live in rural areas. Melo \& $\mathrm{Neto}^{27}$ stated that the anonymity and lack of intimacy associated with social relationships in large urban centers have a negative effect on the QOL of elderly individuals who live in such areas. Similarly, Fonseca ${ }^{28}$ reported that social support networks tend to be more fragile, with inadequate social support, in large cities.

Tavares et al. ${ }^{29}$ also addressed this subject and found interesting results among elderly rural dwellers. These authors assessed 850 elderly residents in a rural area of the municipality of Uberaba-MG using the WHOQOL OLD. They recorded the highest score for the facet intimacy (based on an assessment of social and intimate relationships) and the lowest score for the facet social participation. According to the authors, these results reflect a rural environment that is characterized by interpersonal relationships that are strongly associated with family ties and a lack of opportunities to engage in community activities. Therefore, small towns are attractive to elderly individuals from the point of view of social relationships, which are not affected by the large distances found in rural environments or the fragility of social networks in large urban centers. This issue can be affected by several factors, including the existence of community and leisure centers, and should be investigated in more detail in future studies.

It is important to clarify that the hypotheses presented herein concerning social contact should not be generalized for large cities. Considering that Pimenta Bueno-RO is a small town, it is probable that, despite the fact that geographical difficulties in rural areas can hinder social interaction, they also demand greater physical efforts, favoring the maintenance of higher levels of functional capacity. ${ }^{26,30}$ Functional capacity is one of the most important aspects of self-efficacy and QOL in the elderly population. ${ }^{26,30}$ This could explain why regularly active rural dwellers exhibited higher QOL scores than regularly active urban dwellers in the present study.

Therefore, this process involves a cycle, through which elderly individuals who stay active can overcome geographical barriers and maintain a satisfactory QOL in rural environments. If the individual suffers from some form of disability, certain tasks are abandoned and functional capacity decreases. ${ }^{31}$ Consequently, limitations/disabilities intensify, eventually limiting social contact and affecting the individuals QOL. Thus, physical activity plays a central role in this cycle, particularly for elderly rural dwellers. Interestingly, none of the interviewees in the present study, regardless of where they lived, performed physical activity for leisure. Thus, programs that promote physical activity and awareness could have a positive effect on the elderly individuals in question, particularly those who live in rural areas.

The results of the Spearman test corroborated this line of thought. In rural areas, the PAL was directly correlated with the total, physical, and psychological domains of QOL. Previous studies have proven the psychological benefits of a more active lifestyle. ${ }^{32,33}$ Functional capacity is also important, given that elderly individuals with 
greater functional capacity exhibit greater feelings of self-efficacy and satisfaction with their lives. ${ }^{30}$

A study by Paskulin et al. ${ }^{24}$ demonstrated a positive correlation between the PAL and QOL of elderly individuals, the majority of whom were enrolled in formal physical activity courses. In these locations, other aspects, including social interaction, contribute to the perception of a better QOL. The fact that none of the interviewees, from either of the two groups, performed physical activity for leisure reinforces the fact that the physical activities they do perform (getting around and domestic tasks) are capable of generating significant benefits.

The greater functional capacity that results from a more active lifestyle seems to be the strongest explanation for the results found herein. However, since the present study did not include an assessment of functional capacity, or the quantity and quality of the social network, these statements are mere speculation.

Marital status may also have affected the results. A marginally significant difference $(p=0.06)$ was found between the number of married and nonmarried individuals in rural and urban areas. Only $10 \%(n=2)$ of the rural dwellers were not married, against $40 \%$ of the urban dwellers. Although there are disagreements in the literature, studies have shown that married elderly individuals tend to assess their QOL in better terms than those who are separated or widowed. ${ }^{34,35}$ However, given that the social QOL of the rural dwellers was lower in the present study $(62.9 \pm 13.9$ versus $73.3 \pm 13.4)$, with marginally significant values $(p=0.078)$, it is believed that marital status did not greatly affect the results.

Given these results, both of the initial hypotheses of the present study were discarded, since the PAL values for the urban and rural groups were similar and a correlation between the PAL and QOL scores was only found in the rural group. In the specific case of the town of Pimenta Bueno-RO, the differences observed in the correlation between the PAL and QOL were not expected. Since it is a small town (population of $33,822,13 \%$ of which is rural), ${ }^{1}$ where the infrastructure and services for the elderly population are inadequate, even in the town center, we expected to find a very similar correlation between the PAL and QOL.

The present study contains a number of limitations, such as its cross-sectional design; sample size; the non-inclusion of parameters such as functional capacity and the quality of the social network as well as other parameters that could have affected the QOL, such as income, smoking, diet and comorbidities. Thus, the establishment of cause and effect and the possibility of generalization for other populations were compromised. The use of the IPAQ questionnaire, which could have been affected by the fact that only the week prior to the interview was considered, as well as the inclusion of males and females in the sample, a variable that affects both the PAL and QOL, ${ }^{15,36}$ could also be considered limitations of this research.

\section{CONCLUSION}

Based on the elderly individuals assessed in the present study, the correlation between physical activity level and quality of life was affected by the location (urban or rural). Among elderly rural dwellers, there was a significant, positive and moderate correlation between the physical activity level and the total, physical and psychological domains of quality of life. Insufficiently active elderly individuals in urban areas recorded significantly higher scores in the social domain of quality of life, when compared with insufficiently active elderly rural dwellers. Regularly active elderly individuals living in rural areas scored better in the physical domain of quality of life. 


\section{REFERENCES}

1. Instituto Brasileiro de Geografia e Estatística. Sinopse do Censo Demográfico 2010. Rio de Janeiro: IBGE; 2010.

2. Brum Neto H, Bezzi ML. Ruralidade e representações sociais do Rio Grande do Sul: perspectivas de desenvolvimento regional. In: Formação e contemporaneidade da diversidade sócio-espacial no campo. 19 Encontro Nacional de Geografia Agrária; 2-7 fev 2009; São Paulo. São Paulo: Agrária; 2009. p. 1-21.

3. Weeks WB, Bott DM, Lamkin RP, Wright SM. Veterans health administration and medicare outpatient health care utilization by older rural and urban New England veterans. J Rural Health 2005;21(2):167-71.

4. De Castro JA, Vaz FM. Situação social brasileira : monitoramento das condições de vida. Brasilia, DF: Ipea, 2011.

5. National Rural Health Alliance, Aged and Community Services Australia. Older people and aged care in rural, regional and remote Australia. Melbourne: Aged and Community Services Australia; 2004.

6. Rua J. Urbanidades no rural: o devir de novas territorialidades. Campo Território 2006;1(1):82-106.

7. De Morais EP, Rodrigues RAP, Gerhardt TE. Os idosos mais velhos no meio rural: realidade de vida e saúde de uma população do interior gaúcho. Texto \& Contexto Enferm 2008;17(2):374-83.

8. Camarano AA, Kanso S. Perspectivas de crescimento para a população brasileira: velhos e novos resultados [Internet]. Rio de Janeiro: IPEA; 2009 [05 jun2012]. Disponível em: http://www.ipea.gov.br/portal/index. php?option $=$ com_content $\&$ view $=$ article $\&$ id $=4735$.

9. Wallace AE, Lee R, Mackenzie TA, West AN, Wright $\mathrm{S}$, Booth BM, et al. A longitudinal analysis of rural and urban veterans' health-related quality of life. J Rural Health 2010;26(2):156-63.

10. Alencar NA, Aragão JCB, Ferreira MA, Dantas EHM. Avaliação da qualidade de vida em idosas residentes em ambientes urbano e rural. Rev Bras Geriatr Gerontol 2010;13(1):103-9.

11. Monteiro CA. O envolvimento na prática de atividade física em idosos de meios rurais e urbanos: felicidade, afetos e satisfaçao com a vida [Dissertação]. Porto: Faculdade de Desporto da Universidade do Porto; 2013.
12. Cleary KK, Howell DM. Using the SF-36 to determine perceived health-related quality of life in rural Idaho seniors. J Allied Health 2006;35(3):156-61.

13. Weeks WB, Wallace AE, Wang S, Lee A, Kazis LE. Rural-urban disparities in health-related quality of life within disease categories of veterans. J Rural Health 2006;22(3):204-11.

14. Weeks WB, Kazis LE, Shen Y, Cong Z, Ren XS, Miller D, et al. Differences in health-related quality of life in rural and urban veterans. Am J Public Health 2004;94(10):1762-7.

15. Tsai SY, Chi LY, Lee LS, Chou P. Health-related quality of life among urban, rural, and island community elderly in Taiwan. J Formos Med Assoc 2004;103(3):196-204.

16. Martins CR, De Albuquerque FJB, Gouveia CNNA, Rodrigues CFF, Neves MTS. Avaliação da qualidade de vida subjetiva dos idosos: uma comparação entre os residentes em cidades rurais e urbanas. Estud Interdiscip Envelhec 2007;11:135-54.

17. Beltrame V, Cader SA, Cordazzo F, Dantas EHM. Qualidade de vida de idosos da área urbana e rural do município de Concórdia, SC. Rev Bras de Geriatr Gerontol 2012;15(2):223-31.

18. Marshall TA, Stumbo PJ, Warren JJ, Xie XJ. Inadequate nutrient intakes are common and are associated with low diet variety in rural, communitydwelling elderly. J Nutr 2001;131(8):2192-6.

19. Monteiro CA. A dimensao da pobreza, da fome e da desnutriçao no Brasil. Estud Av 1995;9(24):195-207.

20. Carvalho EO, Da Rocha EF. Consumo alimentar de população adulta residente em área rural da cidade de Ibatiba (ES, Brasil). Ciênc Saúde Coletiva 2011;16(1):179-85.

21. Focchesatto A. Fatores de risco e protectao para o desenvolvimento de doenças cronicas na populacao idosa rural da linha Senador Ramiro, Nova Bassano,RS [Trabalho de Conclusão de Curso]. Rio Grande do Sul: Universidade Federal do Rio Grande do Sul; 2009.

22. Mazo GZ, Benedetti TB, Lopes MA. Atividade física e o idoso: concepção gerontológica. Porto Alegre: Sulina; 2004.

23. Nogueira M, Silva D, Santos J. Actividade física habitual em idosos portugueses rurais e urbanos. Rev Bras Ciênc Mov 2006;14(4):23-30. 
24. Paskulin L, Vianna L, Molzahn AE. Factors associated with quality of life of Brazilian older adults. Int Nurs Rev 2009;56(1):109-15.

25. Fleck MPA, Chachamovich E, Trentini CM. Projeto WHOQOL-OLD: método e resultados de grupos focais no Brasil. Rev Saúde Pública 2003;37(6):793-9.

26. Toscano JJO, De Oliveira ACC. Qualidade de vida em idosos com distintos níveis de atividade física. Rev Bras Med Esporte 2009;15(3):169-73.

27. Melo L, Neto F. Aspectos psicossociais dos idosos em meio rural: solidão, satisfação com a vida e locus de controlo. Psic Educ Cult 2003;7(1):107-21.

28. Fonseca AM. O envelhecimento bem- sucedido. In: Paúl C, Fonseca AM, Coordenadores. Envelhecer em Portugal: psicologia, saúde e prestaçao de cuidados. Lisboa: Climepsi Editores; 2005. p. 281-311.

29. Tavares DMS, Gávea Junior SA, Dias FA, Santos NMF, De Oliveira PB. Qualidade de vida e capacidade funcional de idosos residentes na zona rural. Rev Rene 2011;12:895-903.

30. Asakawa T, Koyano W, Ando T, Shibata H. Effects of functional decline on quality of life among the Japanese elderly. Int J Aging Hum Dev 2000;50(4):319-28.
31. Ramos LR. Fatores determinantes do envelhecimento saudável em idosos residentes em centro urbano: Projeto Epidoso, São Paulo. Cad Saúde Pública 2003;19(3):793-8.

32. Feitosa LR, Tavares C, De Paula FS, Telles S. Benefícios psicológicos e fisiológicos das atividades físicas: uma visão dos idosos. Coleç Pesqui Educ Fís 2008;7(3):69-74.

33. Stella F, Gobbi S, Corazza DI, Costa JLR. Depressão no idoso: diagnóstico, tratamento e benefícios da atividade física. Motriz Rev Educ Fis 2002;8(3):91-8.

34. Andrade JMO, Rios LR, Teixeira LS, Vieira FS, Mendes DC, Vieira MA, et al. Influência de fatores socioeconômicos na qualidade de vida de idosos hipertensos. Ciênc Saúde Coletiva 2014;19(8):3497-504.

35. Perkins AJ, Stump TE, Monahan PO, McHorney CA. Assessment of differential item functioning for demographic comparisons in the MOS SF-36 health survey. Qual Life Res 2006;15(3):331-48.

36. Madeira MC, Siqueira FCV, Facchini LA, De Silveira DS, Tomasi E, Thumé E, et al. Atividade física no deslocamento em adultos e idosos do Brasil: prevalências e fatores associados. Cad Saúde Pública 2013;29(1):165-74 